\title{
Evaluation of updated physical snowpack model SMAP
}

\author{
Masashi NIWANO ${ }^{1}$, Teruo AOKI ${ }^{1}$, Katsuyuki KUCHIKI ${ }^{1}$, Masahiro HOSAKA ${ }^{1}$, Yuji KODAMA ${ }^{2}$, \\ Satoru YAMAGUCHI ${ }^{3}$, Hiroki MOTOYOSHI ${ }^{3}$ and Yukiyoshi IWATA ${ }^{4}$ \\ 1 Meteorological Research Institute, Japan Meteorological Agency, Tsukuba 305-0052, Japan \\ *mniwano@mri-jma.go.jp \\ 2 National Institute of Polar Research, Tachikawa, Tokyo 190-8518, Japan \\ 3 Snow and Ice Research Center, National Research Institute for Earth Science and Disaster Prevention, Nagaoka 940-0821, Japan \\ 4 National Institute for Rural Engineering, National Agriculture and Food Research Organization, Tsukuba 305-8609, Japan
}

(Received December 26, 2013; Revised manuscript accepted March 31, 2014)

\begin{abstract}
The 1D multilayered physical snowpack model Snow Metamorphism and Albedo Process (SMAP), which was originally designed for climate studies, is now updated by incorporating a detailed water movement scheme, realistic snow settlement process and limitation for the Richardson number to ensure minimum turbulent exchanges even under highly stable atmospheric conditions. The evaluation of the updated version of SMAP was first performed using the data obtained at Sapporo, Japan, during the 20072009 winters and the effectiveness of these updates was demonstrated in terms of snow depth and snow surface temperature. However, we pointed out that the choice of maximum Richardson number should be further examined. To test the reliability of SMAP under different climate conditions, we applied it to Naga oka, Japan, during the 2011-2012 winter. At Nagaoka, we performed snow-soil-coupled simulations, because ground heat flux was not available during the study period. For this purpose, we developed a soil submodel for SMAP. Consequently, we confirmed that the updated version performed better than the old version in terms of mass balance simulations at Nagaoka too. Although mass balance-related parameters of the snowpack simulated by the updated version agreed well with observations during the accumulation period, the model substantially overestimated snow depth, as well as column-integrated snow water equivalent during the ablation period. By discussing the reasons for these discrepancies, we highlighted that further investigation on snow-melt processes for thick seasonal snowpack is necessary.
\end{abstract}

Key words: physical snowpack model, Snow Metamorphism and Albedo Process (SMAP), physically based snow albedo model, snow impurity, snow-soil-coupled simulation

\section{Introduction}

A physical snowpack model is a useful tool as it can be employed for a wide range of scientific purposes, including studies on snow physical process, avalanche forecasting and providing boundary conditions for atmospheric general circulation models (GCMs) and regional climate models (RCMs) (Armstrong and Brun, 2008). Among the existing snowpack models, Crocus (Brun et al., 1989, 1992; Vionnet et al., 2012) and SNOWPACK (Bartelt and Lehning, 2002; Lehning et al., 2002a, $2002 b)$, which consider most snow physical processes utilizing multilayered model snow layers, are known to be the most extensive. The most outstanding feature of these two models is that they explicitly take into account the three representative snow metamorphism processes: (1) equi-temperature metamorphism, (2) temperature gradient metamorphism and (3) wet snow metamorphism.
Crocus and SNOWPACK simulate internal snow physical states and energy exchanges between the snow surface and the atmosphere as a function of these metamorphic regimes. Furthermore, they have been successfully applied to various climate regimes around the world, implying that they are physically highly reliable. Indeed, Crocus has been employed in the French Alps (e.g., Rousselot et al., 2010; Morin et al., 2013); the mountainous region of northern Hokkaido, Japan (Hachikubo, 2001); a tropical mountain environment in Ecuador (Wagnon et al., 2009); an Arctic site near Fairbanks, Alaska, USA (Jacobi et al., 2010); and Dome C, Antarctica (Brun et al., 2011). Meanwhile, SNOWPACK has been applied in the Swiss Alps (e.g., Fierz and Lehning, 2001; Lehning et al., 2002b); a mountainous region near Bozeman, Montana, USA (Lundy et al., 2001); Finland (Rasmus et al., 2004); interior Alaska, USA (Saito et al., 2012); Nagaoka and Shinjyo in wet snow region of Japan (Yamaguchi et al., 2004; Saito et al., 2012); Sapporo, Kitami and Niseko in Hokkaido, Japan 
(Hirashima et al., 2004); and Dome C, Antarctica (Groot Zwaaftink et al., 2013).

Recently, Niwano et al. (2012) developed a multilayered physical snowpack model called Snow Metamorphism and Albedo Process (SMAP) to serve for studies on snow physical processes, as well as climate simulations with GCMs or RCMs. SMAP is equipped with a state-ofthe-art physically based snow albedo model (PBSAM) (Aoki et al., 2011), which calculates snow albedo and solar heating profile in the snowpack by explicitly considering its physical characteristics: the near-infrared albedo is strongly affected by snow grain size (Wiscombe and Warren, 1980), while the visible albedo depends on snow impurities such as black carbon (BC) and dust (Warren and Wiscombe, 1980). Niwano et al. (2012) performed detailed validations of SMAP in terms of snow depth, column-integrated snow water equivalent (SWE), columnaverage snow density, snow grain shape profile, snow surface temperature, (optically equivalent) snow grain size defined by Aoki et al. (2007) in the top $2 \mathrm{~cm}$ of the snowpack and broadband albedos using the data obtained at Sapporo, Japan, during the 2007-2009 winters. Consequently, it was demonstrated that SMAP successfully reproduced all the observed variations of the physical properties of the snowpack for both winters. However, several inadequacies were revealed: (1) overestimation of snow depth, especially during the warm 2008-2009 winter when air temperatures were often above $0^{\circ} \mathrm{C}$, even in the accumulation period and (2) underestimation of snow surface temperature especially under very stable conditions.

In this study, we attempted to perform model improvements to overcome the problems mentioned above. Specifically, we introduced physically realistic schemes for water movement in the snowpack and snow settlement to improve snow depth simulations and examined the treatment of turbulent heat exchanges under very stable conditions to inhibit underestimation of snow surface temperature. The effects of these model updates were inspected using the same data as Niwano et al. (2012) used, which were obtained at Sapporo, Japan during the 2007-2008 and 2008-2009 winters (November to April). Next, the updated version of SMAP (hereafter, referred to as "new_ctl”) as well as old version of SMAP (hereafter, called as "old_ctl”) were applied to Nagaoka, Japan, which is located in one of the heaviest snow-fall regions in Japan. Because heat flux at the ground surface (ground heat flux), which is suitable for the bottom boundary condition of numerical simulations with the energy conservation equation of the snowpack, was not measured at Nagaoka during the period of interest, we introduced a soil submodel into SMAP to provide the boundary condition of the snowpack, described in Section 2.3.4. The purpose of performing model evaluations under several different climate conditions is to test the reliability of SMAP.

\section{Materials and methods}

\subsection{Field measurements}

2.1.1 2007-2009 Winters at Sapporo, Japan

During the 2007-2009 winters, we carried out meteorological measurements using an automated weather station (AWS) installed at the Institute of Low Temperature Science, Hokkaido University $\left(43^{\circ} 05^{\prime} \mathrm{N}, 141^{\circ}\right.$ $21^{\prime} \mathrm{E}, 15 \mathrm{~m}$ a.s.l), which is located in an urban area within Sapporo city, Hokkaido, Japan (Aoki et al., 2006). In addition, we performed snow pit measurements and snow sampling twice a week at approximately 1100 local time near the AWS. The observed parameters used to drive SMAP were the same as those used by Niwano et al. (2012), which are precipitation corrected by considering catch efficiencies for snow and rain as functions of gauge type and wind speed employing algorithms by Yokoyama et al. (2003), air pressure, wind speed, air temperature, relative humidity, downward shortwave (wavelength $\lambda$ $=0.305-2.8 \mu \mathrm{m})$ and near-infrared $(\lambda=0.708-2.8 \mu \mathrm{m})$ radiant fluxes, diffuse components of shortwave and nearinfrared radiant fluxes, downward longwave radiant flux, ground heat flux, column-integrated SWE and mass concentrations of snow impurities (BC and dust) for the top 2 and $10 \mathrm{~cm}$ snow layers obtained from collected snow samples (Kuchiki et al., 2009; Aoki et al., 2011). Because the downward ultraviolet (UV)-visible radiant flux was not measured directly, it was calculated by subtracting the measured downward near-infrared radiant flux from the measured downward shortwave radiant flux. For meteorological input data we used data averaged every $30 \mathrm{~min}$. The procedure to input mass concentrations of snow impurities into SMAP was the same as used by Niwano et al. (2012), where the values in the top $2 \mathrm{~cm}$ layers of the model snowpack were equated to the corresponding observed values, while for the lower layers of the model snowpack, the observed values for the top $10 \mathrm{~cm}$ of the snowpack were used. The data gaps of mass concentrations of snow impurities for the days between snow pit observations were filled using the values measured at the preceding points in time (Niwano et al., 2012). For model evaluation, we used snow depth and snow surface temperature measured with the AWS and column-integrated SWE from snow pit measurements. In the following sections, we refer to November, December, January and February as the "accumulation period" and March and April as the "ablation period."

\subsubsection{1-2012 Winter at Nagaoka, Japan}

Nagaoka is located in one of the heaviest snow-fall regions in Japan and the dominant snow grain shape is melt forms, because of the continuous formation and percolation of melt water throughout the entire winter period (Yamaguchi et al., 2004). Therefore, it is worth testing the performance of SMAP developed and evaluated with the data measured at Sapporo, where dry 
snow is predominant during the accumulation period (Niwano et al., 2012). In the present study, we employed meteorological data measured with an AWS installed in the observation field of the Snow and Ice Research Center, National Research Institute for Earth Science and Disaster Prevention (NIED), located in Nagaoka city, Niigata, Japan, $\left(37^{\circ} 25^{\prime} \mathrm{N}, 138^{\circ} 53^{\prime} \mathrm{E}, 97 \mathrm{~m}\right.$ a.s.l) during the 2011-2012 winter; we also used snow pit measurements conducted once a week (National Research Institute for Earth Science and Disaster Prevention, Japan, 2012). The observed forcing parameters for SMAP model simulations at Nagaoka are hourly precipitation, air pressure, wind speed, air temperature, relative humidity, downward shortwave and near-infrared radiant fluxes and downward longwave radiant flux. Again, the downward UV-visible radiant flux was calculated from measured downward shortwave and near-infrared radiant fluxes in the same manner as for Sapporo (Sect. 2.1.1.). At Nagaoka, we did not measure diffuse fractions of UVvisible and near-infrared radiant fluxes. Therefore, they were simulated by SMAP using the scheme of Goudriaan (1977) as functions of internally calculated cloud fraction (Niwano et al., 2012) and solar zenith angle. Uncertainties in SMAP model simulations caused by this calculation process are assessed using the data obtained at Sapporo in Sect. 3.1. For the precipitation data, we corrected the measured precipitation by calculating catch efficiencies for snow and rain as functions of gauge type and wind speed using algorithms developed by Yokoyama et al. (2003), as performed for the case at Sapporo by Niwano et al. (2012). Because ground heat flux was not available at Nagaoka, we performed coupled simulations between the snowpack and the underlying soil using a newly developed soil submodel for SMAP introduced in Sect. 2.3.4. To initialize the soil physical states, the observed soil temperatures (at 10, 20, 50, 80, 100 and $150 \mathrm{~cm}$ in depths) were utilized. In addition, we performed snow sampling at several different times to acquire the mass concentration of snow impurities in the top $0-2 \mathrm{~cm}$ and $0-10 \mathrm{~cm}$ layers during the winter in the same manner as that for Sapporo, allowing us to input them into SMAP in a similar way to that employed at Sapporo. For performing the model evaluation at Nagaoka, we employed snow depth, column-integrated SWE, soil temperature and snow surface temperature measured with the AWS. We also introduced column-average snow density calculated from observed snow depth and columnintegrated SWE. The snow surface temperature was obtained from the observed downward and upward longwave radiant fluxes assuming the emissivity of the snow surface to be 0.98 (Armstrong and Brun, 2008). In addition to volumetric water content profiles obtained from snow density and water weight content measured with a dielectric probe (Denoth, 1994), regular snow pit measurements were used.

\subsection{SMAP model overview}

Using the input parameters listed in Sect. 2.1., the 1D physical snowpack model SMAP calculates the temporal evolution of the physical characteristics of snow by considering energy balance, mass balance, snow settlement, phase changes, water percolation and snow metamorphism. Here precipitation included in the input parameters are partitioned into snow and rain by using the algorithm to calculate snow:rain ratios as a function of wet bulb temperature introduced by Yamazaki (1998, 2001).

The PBSAM component of SMAP calculates snow albedo and solar heating profiles by using profiles of snow grain size and SWE internally calculated by SMAP, together with the mass concentrations of snow impurities externally provided by in situ measurements or host GCMs or RCMs. Snow grain size is calculated using a model geometry that envisions two spherical ice particles connected by a neck (Lehning et al., 2002a). SMAP obtains snow grain sizes by calculating the specific surface area (SSA) of snow per unit volume with the nonspherical model geometry. SMAP calculates the temporal evolution of snow grain size using the same formulations as SNOWPACK (Lehning et al., 2002a), which takes equi-temperature metamorphism, temperature gradient metamorphism and wet snow metamorphism into consideration. Furthermore, SMAP implicitly considers the effects of snow metamorphism under alternating temperature gradients (Pinzer and Schneebeli, 2009) by forcing temperature gradient metamorphism not to occur in the top $20 \mathrm{~cm}$ of the model layers.

To calculate temporal evolution of physical states of snowpack, SMAP approximates and solves the 1D energy balance equation with the Crank-Nicolson finite difference implicit method where Neumann boundary conditions, which is prescribed in terms of snow temperature gradients at both the snow surface and the bottom of the snowpack, are imposed (Niwano et al., 2012). Here SMAP assumes each model snow layer to have a thickness $d$ that is allowed to range between $d_{\min }$ and $d_{\max }$ (values set in this study are explained in Sect. 2.4.). When new snow falls or surface hoar forms, SMAP adds a new snow layer to the top of the snowpack.

\subsection{Model updates}

\subsubsection{Water movement in the snowpack}

In the original version of SMAP (Niwano et al., 2012) (old_ctl), water percolation was controlled by means of the mass fraction of water, where liquid water fraction greater than the prescribed maximum mass fraction of water is assumed to descend to the adjacent lower layer. Niwano et al. (2012) pointed out that this simple treatment of water movement in the snowpack could sometimes be unrealistic and inadequate, especially during the accumulation period, leading to errors in mass balance simulations. Therefore, to improve water movement processes in the snowpack, we have incorporated the 
Richards equation (Richards, 1931), which considers Darcy's law:

$$
\frac{\partial \theta}{\partial t}=\frac{\partial}{\partial z}\left(D \frac{\partial \theta}{\partial z}-K\right),
$$

where $\theta$ is volumetric water content, $t$ is time, $D$ is hydraulic diffusivity and $K$ is hydraulic conductivity. The formulations for $D$ and $K$ are taken from the van Genuchten model (van Genuchten, 1980) as follows:

$$
\begin{aligned}
& K=K_{s} \Theta^{1 / 2}\left[1-\left(1-\Theta^{1 / m}\right)^{m}\right]^{2}, \\
& D=\frac{(1-m) K_{s}}{\alpha m\left(\theta_{s}-\theta_{r}\right)} \Theta^{1 / 2-1 / m}\left[\left(1-\Theta^{1 / m}\right)^{-m}+\left(1-\Theta^{1 / m}\right)^{m}-2\right],
\end{aligned}
$$

$$
m=1-\frac{1}{n},
$$

and

$$
\Theta=\left(\frac{\theta-\theta_{r}}{\theta_{s}-\theta_{r}}\right),
$$

where $K_{s}$ is the saturated hydraulic conductivity, $\Theta$ is the effective water saturation, $\theta_{\mathrm{s}}$ is the volumetric water content when liquid water has filled the available snow pore space, $\theta_{\mathrm{r}}$ is the irreducible water saturation (it indicates the volumetric content of water permanently retained by capillary forces) and $\alpha, m$ and $n$ are model parameters. To obtain $K_{s}, \alpha$ and $n$, we adopted following formulations by Shimizu (1970), Hirashima et al. (2010), Yamaguchi et al. (2010) and Yamaguchi et al. (2012) developed from laboratory experiments:

$$
\begin{aligned}
& K_{s}=7.7 \times 10^{-4}\left(2 r_{g}\right)^{2} \frac{g}{\nu} \exp \left(-7.8 \times 10^{-3} \rho_{s}\right), \\
& \alpha=4.4 \times 10^{6}\left(\frac{\rho_{s, d r y}}{2 \times 10^{-3} r_{g}}\right)^{-0.98},
\end{aligned}
$$

and

$$
n=1+2.7 \times 10^{-3}\left(\frac{\rho_{s, d r y}}{2 \times 10^{-3} r_{g}}\right)^{0.61},
$$

where $r_{g}(\mathrm{~mm})$ is geometrical snow grain size, $g$ is the gravitational constant, $\nu$ is the kinetic viscosity coefficient of water at $0^{\circ} \mathrm{C}, \rho_{\mathrm{s}}$ is snow density $\left(\mathrm{kg} \mathrm{m}^{-3}\right)$ and $\rho_{\mathrm{s}, \mathrm{d} r y}$ is dry snow density $\left(\mathrm{kg} \mathrm{m}^{-3}\right)$. The other snow physical parameters of $\theta_{\mathrm{s}}$ and $\theta_{\mathrm{r}}$ were set to be $90 \%$ of the porosity and 0.02 , respectively, as given by Yamaguchi et al. (2012). In SMAP, snow grain size is defined as the optically equivalent snow grain size, which is generally smaller than the geometrical snow grain size. Although SMAP diagnoses geometrical snow grain size from optically equivalent snow grain size at every time step (Niwano et al., 2012), it is still smaller than observations. Therefore, we multiplied the geometrical snow grain size by a factor calculated from a ratio between the geometrical new snow grain size set in SNOWPACK (Lehning et al., 2002a) $(0.15 \mathrm{~mm})$ and SMAP calculated geometrical new snow grain size to obtain $r_{g}$. The Richards equation (Eq. (1)) is numerically solved by the finite difference implicit method to obtain the time evolution of the volumetric water content profile.

\subsubsection{Snow settlement}

Although the SMAP old_ctl could reproduce seasonal variations of column-average snow density for the 20072008 and 2008-2009 winters at Sapporo, it turned out that SMAP old_ctl was prone to underestimate the columnaverage snow density, and that this tendency was more pronounced during the warm 2008-2009 winter when air temperature were often above $0^{\circ} \mathrm{C}$, even during accumulation period, and the snowpack was often subject to wet snow conditions (Niwano et al., 2012). This error caused the failure of snow depth simulations. Thus, to solve the densification equation incorporated in SMAP, we employed a detailed scheme for the viscosity coefficient of snow $\eta$ developed to improve the performance of Crocus by Vionnet et al. (2012), instead of the original relatively simple scheme developed by Bader and Weilenmann (1992) and Morris et al. (1997). The new scheme incorporates the effects of snow density, snow temperature, absolute liquid water content and geometric snow grain size on the snow settlement as follows:

$$
\eta=f_{1} f_{2} \eta_{0} \frac{\rho_{s}}{c_{\eta}} \exp \left(a_{\eta}\left(T_{\text {fus }}-T_{s}\right)+b_{\eta} \rho_{s}\right),
$$

where $\eta_{0}=7.62237 \times 10^{6} \mathrm{~kg} \mathrm{~s}^{-1} \mathrm{~m}^{-1}, a_{\eta}=0.1 \mathrm{~K}^{-1}, b_{\eta}=$ $0.023 \mathrm{~m}^{3} \mathrm{~kg}^{-1}, c_{\eta}=250 \mathrm{~kg} \mathrm{~m}^{-3}, T_{\text {fus }}$ is the temperature of the water melting point, $T_{s}$ is the snow temperature and $f_{1}$ and $f_{2}$ are defined as:

$$
f_{1}=\frac{1}{1+60 \frac{W_{l i q}}{\rho_{W} d}}
$$

and

$$
f_{2}=\min \left[4.0, \exp \left(\min \left(g_{1}, 2 r_{g}-g_{2}\right) / g_{3}\right)\right],
$$

where $W_{l i q}$ is the absolute water content in each model layer $\left(\mathrm{kg} \mathrm{m}^{-2}\right), \rho_{\mathrm{w}}$ is the density of water, $d$ is the model layer thickness, $g_{1}=0.4 \mathrm{~mm}, g_{2}=0.2 \mathrm{~mm}$ and $g_{3}=0.1 \mathrm{~mm}$.

\subsubsection{Turbulent heat exchanges under very stable conditions}

Accurate simulation of the night time snow surface temperature under calm and clear sky conditions is a challenging topic for any snowpack model, as sensible heat flux $H_{S}$ calculated by bulk method tends to be underestimated under these stable atmospheric conditions (e.g., Martin and Lejeune, 1998; Helgason and Pomeroy, 2012; Niwano et al., 2012). Niwano et al. (2012) pointed out that a possible reason for the underestimation for SMAP is the calculation procedure of the turbulent heat fluxes, including $H_{S}$ and the latent heat flux $H_{L}$, calculated by the bulk method, in which $H_{S}$ and $H_{L}$ were set to be 0 when the bulk Richardson number exceeded the critical Richardson number (in Niwano et al. (2012) 0.25 was 
selected). Thus, in SMAP new_ctl, we set a limitation for the bulk Richardson number (i.e., a maximum Richardson number) to ensure minimum turbulent exchanges, even under very stable conditions, and bind the maximum Richardson number to 0.1 following Brun et al. (2011).

\subsubsection{Soil submodel}

It is useful to employ observed ground heat flux as the boundary condition of snow temperature evolution simulations (the Neumann boundary condition) (e.g., Niwano et al., 2012). When the ground heat flux is not available, constant bottom snow temperature of $0^{\circ} \mathrm{C}$ (the Dirichlet boundary condition) or constant ground heat flux are often assumed. However, these simple assumptions could lead to errors in snow-melt simulations, because heating from the ground to the snowpack cannot be assessed realistically with either of these assumptions. On the basis of this consideration, we developed a soil submodel for SMAP to provide the realistic ground heat flux into the snowpack at Nagaoka, for which the measurements of ground heat flux were unavailable during the 2011-2012 winter. In this section, the formulations of the soil submodel are described briefly.

The 1D governing equation of the soil submodel is the energy conservation equation that considers phase changes and convection flow (e.g., Jansson and Karlberg, 2001):

$$
c_{g} \frac{\partial T}{\partial t}=\frac{\partial}{\partial z}\left(k_{g} \frac{\partial T}{\partial z}\right)+L_{f} \rho_{w} \frac{\partial \theta_{i}}{\partial t}-c_{w} T \frac{\partial q_{w}}{\partial z}-L_{v} \frac{\partial q_{v}}{\partial z}
$$

where $c_{g}$ is the heat capacity of soil, $T$ is the soil temperature, $k_{g}$ is the thermal conductivity of soil, $L_{f}$ is the latent heat of fusion, $\theta_{\mathrm{i}}$ is the volumetric ice content, $c_{w}$ is the heat capacity of water, $q_{w}$ is water flux, $L_{v}$ is the latent heat of evaporation and $q_{v}$ is vapor flux. To obtain the temporal evolution of soil temperature, SMAP numerically solves Eq. 12 using the finite difference implicit method. Herein, we take 170 model layers with varying thicknesses $d$ in soil with an overall thickness of $1000 \mathrm{~cm}$. Specifically, $d$ is equally set to be $1 \mathrm{~cm}$ in the top $20 \mathrm{~cm}, 2 \mathrm{~cm}$ at depths of $20-100 \mathrm{~cm}, 5 \mathrm{~cm}$ at depths of $100-300 \mathrm{~cm}$ and $10 \mathrm{~cm}$ at depths greater than $300 \mathrm{~cm}$. The boundary condition of Eq. 12 at the soil surface was given by the Neumann type condition, which is a consequence of the surface energy balance and essentially the same as that employed in the snowpack simulation explained by Niwano et al. (2012). At the bottom of the soil, we also selected the Neumann boundary condition, with zero flux assumed. The thermal conductivity of soil $k_{g}$ in Eq. 12 was calculated using the parameterization by Peters-Lidard et al. (1998):

$$
k_{g}=K_{e}\left(k_{s a t}-k_{d r y}\right)+k_{d r y},
$$

where $K_{e}$ is the Kersten number (a function of the degree of soil saturation), $k_{\text {sat }}$ is saturated soil thermal conductivity and $k_{d r y}$ is dry soil thermal conductivity. The two types of thermal conductivities $\left(k_{s a t}\right.$ and $\left.k_{d r y}\right)$ were given as functions of soil porosity and quartz content, respectively.

At the same time, we considered water flow in the soil using exactly the same equation as that employed for the water movement simulations in the snowpack described in Sect. 2.3.1. (Richards equation: Eq. 1). Again, in this soil submodel, the hydraulic diffusivity $D$ and the hydraulic conductivity $K$ are calculated from the van Genuchten model (van Genuchten, 1980) as functions of saturated hydraulic conductivity $K_{s}$ and model parameters $\alpha$ and $n$.

Ultimately, the problem comes down to the question of how to determine the five unknown parameters of soil porosity, quartz content, $K_{s}, \alpha$ and $n$. Although these parameters are largely controlled by soil types (e.g., Peters-Lidard et al., 1998; van Genuchten, 1980), they are highly site-specific. Therefore, it is ideal to perform in situ measurements of these soil physical parameters, as conducted by Iwata et al. (2010), when a parameterization by Peters-Lidard et al. (1998) or the van Genuchten model is employed strictly. However, in the present study, we focus only on providing realistic ground heat flux from the soil to the snowpack using the soil submodel; therefore, seeking precise soil properties in Nagaoka is beyond the scope of this paper. In the following numerical simulations, the soil porosity and quartz content were given from Peters-Lidard et al. (1998), the three van Genuchten model parameters were taken from a list presented by van Dam and Feddes (2000) and we provisionally assumed the soil type to be clay.

\subsection{Model simulations and evaluation}

SMAP requires some model input parameters: the number of subbands to be used in PBSAM, time step $\Delta t$ and minimum and maximum model snow layer thicknesses $d_{\min }$ and $d_{\max }$ (Niwano et al., 2012). Following Niwano et al. (2012), we employed four subbands for both the UV-visible and near-infrared bands in PBSAM, set $\Delta t$ $=50 \mathrm{~s}$ and forced the model snow layer thickness to the range between $d_{\text {min }}=0.5 \mathrm{~cm}$ and $d_{\max }=3 \mathrm{~cm}$. In every time step, the forcing variables explained in Sect. 2.1., which were updated every $30 \mathrm{~min}$, were used. In the numerical simulations carried out at Nagaoka, additional site-specific settings for new snow density and roughness length for momentum of the snow surface were considered. At present, SMAP is equipped with the functions for new snow density $\rho_{\text {s, new }}$ introduced by Yamazaki (1998, 2001), Kajikawa (1989) and Lehning et al. (2002b). When SMAP was applied at Sapporo, we employed the function by Yamazaki $(1998,2001)$, because it was developed and well validated under the climate condition at Sapporo (Niwano et al., 2012). However, in the present case, we selected the following function by Kajikawa (1989) in order to exclude effects due to new snow density calculation on total model performance as much as possible: 


$$
\rho_{s, \text { new }}=3.6 u-0.2 T_{a}+62,
$$

where $u$ is wind speed and $T_{a}$ is air temperature. The usefulness of this function for wet snow condition at Nagaoka has been confirmed by SNOWPACK simulations conducted by Yamaguchi et al. (2004) and Saito et al. (2012). The roughness length for momentum $z_{0}$ is set to be $7 \times 10^{-4} \mathrm{~m}$ following Yamaguchi et al. (2004).

Initially, evaluation of SMAP new_ctl was conducted at Sapporo (2007-2009 winters) by introducing the indices of root mean square error (RMSE) and mean error on model accuracy ( $M E$ : the average of the difference between simulated values and observed values), which were obtained from a comparison of measured and simulated data. In Sect. 3.1, using the same data as Niwano et al. (2012) employed, we demonstrated the effects of the three newly implemented snow physical schemes (water movement, snow settlement and treatment of turbulent heat exchanges under very stable conditions) on snow depth (as well as column-integrated SWE) and snow surface temperature by comparing the results from new_ctl with those from old_ctl (Niwano et al., 2012). Furthermore, we investigated the individual effects of each scheme by model sensitivity tests, where every scheme was sent back to the old ones from new ctl, as explained in Section 2.3. In the following, we refer to these numerical sensitivity tests as "new_st1," “new_ st2," and "new_st3." They are essentially the same as "new_ctl" but employ old schemes for water movement (water percolation in the snowpack is controlled by mass fraction of water), snow settlement (Bader and Weilenmann, 1992; Morris et al., 1997) and turbulent heat exchanges under stable conditions $\left(H_{S}\right.$ and $H_{L}$ were set to be 0 when the bulk Richardson number exceeded the critical Richardson number). In addition, we performed another sensitivity test named as "new_dfc" to assess impacts of the scheme of Goudriaan (1977), which calculates diffuse fractions of UV-visible and near-infrared radiant fluxes. In new_dfc, model settings are definitely as same as new_ctl, but diffuse fractions of UV-visible and near-infrared radiant fluxes are calculated by SMAP itself using the scheme. The purpose of this test is to comprehend uncertainties caused by the scheme that is employed as default at Nagaoka, where these radiant fluxes are not available.

Further model validation was performed using the data obtained at Nagaoka during the 2011-2012 winter. At Nagaoka, the newly developed soil submodel was coupled to SMAP to provide realistic ground heat flux into the snowpack. As mentioned in Sect. 2.1.2., observed soil temperatures (at 10, 20, 50, 80, 100 and $150 \mathrm{~cm}$ depths) were utilized to initialize the soil temperature profile. In the model soil layers (explained in Sect. 2.3.4.) shallower than $150 \mathrm{~cm}$ in depth, initial soil temperatures were calculated by linear interpolation using the observed data, while initial soil temperatures at depths greater than $150 \mathrm{~cm}$ were equated simply with the observed soil temperature at $150 \mathrm{~cm}$ depth. The validated parameters were snow depth, column-integrated SWE, columnaverage snow density, soil temperature profile, profiles of volumetric water content of snow and snow surface temperature. The validity of the calculated ground heat flux by the soil submodel is implicitly assessed from the simulated soil temperature profile in Sect. 3.2.

\section{Results and discussion}

\subsection{Sapporo}

\subsubsection{Meteorological and snow conditions}

Meteorological conditions during the 2007-2008 and 2008-2009 winters at Sapporo were contrasting in terms of temperature. Average daily mean air temperatures during the period from December to March, when the snowpack existed continuously for both winters, were $-1.58^{\circ} \mathrm{C}$ for the first winter and $-0.34^{\circ} \mathrm{C}$ for the second (Niwano et al., 2012). Although accumulated precipitation during the period from November to April was $385 \mathrm{~mm}$ for the first winter and $438 \mathrm{~mm}$ for the second, the snow depth after late January was greater during the first winter than the second. As for the near-surface mass concentrations of snow impurities (BC and dust), they were almost the same during the two winters. Median mass concentrations of dust and $\mathrm{BC}$ in the top $2 \mathrm{~cm}$ snow layers were 4.63 and $0.217 \mathrm{ppmw}$ for the first winter, and 3.86 and $0.207 \mathrm{ppmw}$ for the second, which are much higher than in situ measurement results obtained in the Arctic (Aoki et al., 2011).

\subsubsection{Snow depth}

Figures $1 \mathrm{a}$ and $1 \mathrm{~b}$ compares the time series of observed and simulated (with old_ctl and new_ctl) snow depths at Sapporo during the 2007-2008 and 2008-2009 winters. In both winters the tendency of SMAP old_ctl to overestimate snow depth was reduced in new_ctl. Although the timing of complete melting during the 2008-2009 winter in the old_ctl simulation was delayed from that in 2007-2008 (by about a week), the simulation by new_ctl agreed with the observation satisfactorily. In fact, the $M E$ values were reduced from 0.045 to $0.009 \mathrm{~m}$ and from 0.044 to $0.014 \mathrm{~m}$ for the 2007-2008 and 20082009 winters, respectively (Table 1). The RMSE values were also reduced ( 0.064 to $0.045 \mathrm{~m}$ and 0.075 to $0.050 \mathrm{~m}$ for each winter, respectively), suggesting that overall model performance was improved in new_ctl. The most effective process for inducing this improvement was examined from the three sensitivity tests: new_st1, new_ st2 and new_st3 (Table 1). While the RMSE obtained from new_st1 and new_st3 were almost the same as that from new_ctl, that from new_st2 was obviously larger than that from new_ctl for both winters, implying that the newly implemented snow settlement scheme by Vionnet et al. (2012) (Sect. 2.3.2.) played the most important role in improving the accuracy of snow depth simulations at Sapporo during both winters. In order to 

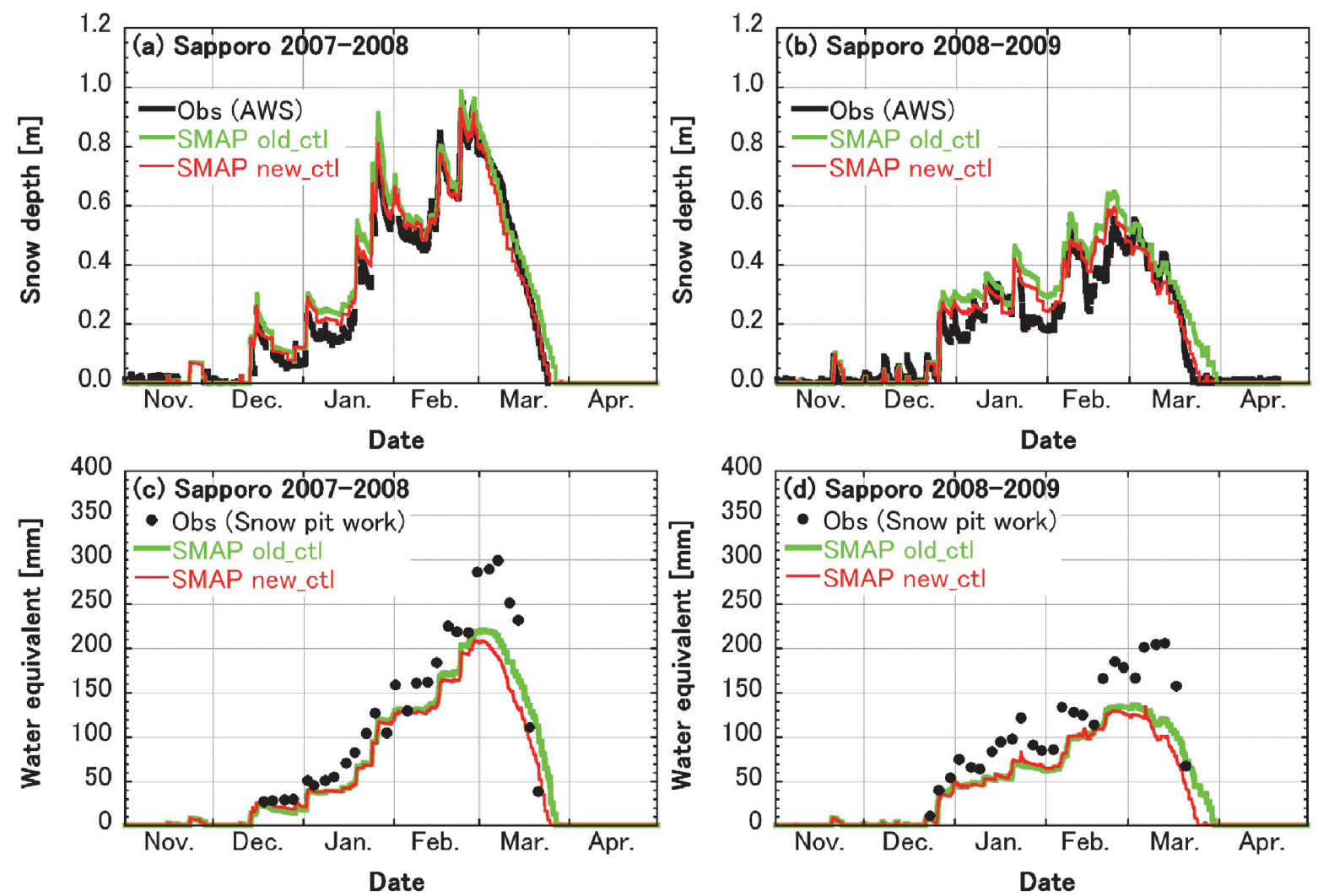

Fig. 1. Seasonal evolution of observed (a, b) snow depth (black solid curves) and (c, d) column-integrated snow water equivalent (SWE) (black dots) during the 2007-2008 and 2008-2009 winters at Sapporo, Japan. Temporal changes in snow depth and SWE simulated with SMAP (green solid curves for the old version "old_ctl" and red solid curves for the updated version "new_ctl") are also depicted.

Table 1. Comparison of SMAP simulation results with in situ measurements in terms of snow depth during 20072009 winters at Sapporo, Japan. Experiments refer to model settings: "old_ctl" follows the old control setting by Niwano et al. (2012) and "new_ctl" is the updated version presented in this study. Three sensitivity tests indicated by "new_st1," "new_st2," and "new_st3" are the same as "new_ctl," except that they employ old schemes for water movement, snow settlement and turbulent heat exchanges under stable conditions, respectively. Additional experiment "new_dfc" is the same as "new_ctl", but it calculates diffuse fractions of UV-visible and near-infrared radiant fluxes using the scheme of Goudriaan (1977). RMSE and $M E$ are abbreviations for root mean square error and mean error (the average of the difference between simulated values and observed values), respectively.

\begin{tabular}{rlccc}
\hline Parameter & Experiments & Period & $R M S E$ & $M E$ \\
\hline & old & $\mathbf{2 0 0 7 - 2 0 0 8}$ & $\mathbf{0 . 0 6 4}$ & $\mathbf{0 . 0 4 5}$ \\
& new_ctl & " & $\mathbf{0 . 0 4 5}$ & $\mathbf{0 . 0 0 9}$ \\
& new_st1 & " & 0.043 & 0.016 \\
& new_st2 & "' & 0.063 & 0.004 \\
& new_st3 & " & 0.048 & 0.028 \\
Snow depth $[\mathrm{m}]$ & new_dfc & " & 0.058 & 0.029 \\
& old & $\mathbf{2 0 0 8 - 2 0 0 9}$ & $\mathbf{0 . 0 7 5}$ & $\mathbf{0 . 0 4 4}$ \\
& new_ctl & " & $\mathbf{0 . 0 5 0}$ & $\mathbf{0 . 0 1 4}$ \\
& new_st1 & " & 0.052 & 0.018 \\
& new_st2 & " & 0.060 & 0.021 \\
& new_st3 & " & 0.052 & 0.021 \\
& new_dfc & " & 0.057 & 0.024 \\
\hline
\end{tabular}

verify the usefulness of the newly improved snow settlement process, we compared column-integrated SWE obtained from old_ctl and new_ctl in Figs. 1c and 1d. These figures denote that simulated column-integrated SWE by old_ctl and new_ctl are almost on the same order during accumulation period, however, mass loss was enhanced in new_ctl especially at the beginning of ablation period for both winters. This result implies that the newly implemented snow settlement scheme by Vionnet et al. (2012) performs reasonably during accumulation period at Sapporo, however, its efficiency during ablation period should be further inspected.

In addition, we investigated impacts of the scheme by Goudriaan (1977) on SMAP model performance. 

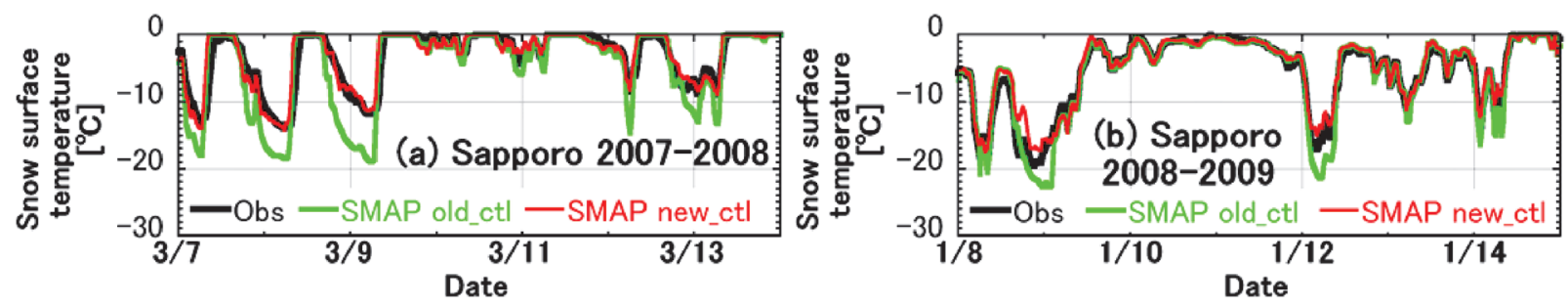

Fig. 2. Examples of snow surface temperature comparisons between observation (black solid curves) and simulations (green solid curves for the old version "old_ctl" and red solid curves for the updated version "new ctl”) during the (a) 2007-2008 and (b) 2008-2009 winter at Sapporo, Japan.

Table 2. As Table 1, but for snow surface temperature.

\begin{tabular}{clccc}
\hline Parameter & Experiments & Period & $R M S E$ & $M E$ \\
\hline & old & $\mathbf{2 0 0 7 - 2 0 0 8}$ & $\mathbf{2 . 4 5}$ & $\mathbf{- 0 . 3 0}$ \\
& new_ctl & " & $\mathbf{2 . 0 3}$ & $\mathbf{0 . 6 2}$ \\
& new_st1 & " & 1.82 & 0.53 \\
& new_st2 & "' & 2.12 & 0.63 \\
Snow surface temperature $\left[{ }^{\circ} \mathrm{C}\right]$ & new_st3 & "' & 2.40 & -0.05 \\
& new_dfc & "I & 1.91 & 0.45 \\
& old & $\mathbf{2 0 0 8 - 2 0 0 9}$ & $\mathbf{2 . 0 3}$ & $\mathbf{- 0 . 6 7}$ \\
& new_ctl & " & $\mathbf{1 . 5 0}$ & $\mathbf{- 0 . 1 3}$ \\
& new_st1 & " & 1.42 & -0.20 \\
& new_st2 & " & 1.49 & -0.14 \\
& new_st3 & " & 1.88 & -0.49 \\
& new_dfc & " & 1.49 & -0.10 \\
\hline
\end{tabular}

Comparison of the RMSE and $M E$ values obtained from new_dfc against those from new_ctl indicates they are almost equal.

\subsubsection{Snow surface temperature}

The other issue to be resolved for old_ctl was the underestimation of snow surface temperature, especially during stable atmospheric conditions. Fig. 2 gives examples of significant underestimation of snow surface temperature by old_ctl during the 2007-2009 winters at Sapporo, as discussed by Niwano et al. (2012). On the contrary, in new_ctl, the bias has been fixed and simulation results fitted observations better. From the statistical point of view (Table 2), $M E$ was improved in new_ctl during the $2008-2009$ winter $\left(-0.67^{\circ} \mathrm{C}\right.$ to $-0.13^{\circ} \mathrm{C}$ ). However, during the $2007-2008$ winter, the sign of $M E$ turned from negative to positive and the absolute model bias increased $\left(-0.30^{\circ} \mathrm{C}\right.$ to $\left.0.62^{\circ} \mathrm{C}\right)$. The reason for these changes can be mainly attributed to treatment of turbulent heat exchanges under very stable conditions, as indicated by the relatively large differences in RMSE and ME between new_ctl and new_st3 (Table 2). In SMAP sensible heat flux $H_{s}$ is calculated as follows (Niwano et al., 2012):

$$
H_{S}=\rho_{a} c_{p a} C_{H} u\left(\theta-\theta_{s 0}\right),
$$

where $\rho_{\mathrm{a}}$ is the density of air, $c_{p a}$ is the specific heat capacity of air at constant pressure, $C_{H}$ is the bulk transfer coefficient for sensible heat and $\theta$ and $\theta_{\mathrm{s} 0}$ are potential temperature at measurement height of air temperature (1.5 $\mathrm{m}$ at Sapporo and $3.5 \mathrm{~m}$ at Nagaoka) and the snow surface, respectively. In practice, $C_{H}$ is diagnosed at every time step considering atmospheric stability conditions (Niwano et al., 2012). The new treatment introduced in Sect. 2.3.3. generally acts to increase $C_{H}$, and heating from the atmosphere to the snow surface can be reinforced, even under very stable conditions. In new_ctl the smaller maximum Richardson number gives the larger $H_{S}$ (i.e., surface heating is enhanced). Therefore, a possible cause for the deterioration in $M E$ during the 2007-2008 winter could be the choice of the maximum Richardson number. To increase the model accuracy, the appropriate value for the maximum Richardson number should be further explored.

In the end, we investigated effects of the scheme by Goudriaan (1977) on SMAP simulated snow surface temperature by results from new_dfc. As a result, we could confirm the RMSE and $M E$ values obtained from new_dfc were also on the same level with those from new_ctl, and the scheme is useful when diffuse fractions of UV-visible and near-infrared radiant fluxes are not available.

\subsection{Nagaoka}

In this section, we apply SMAP to the snow at Nagaoka. It is worth testing and validating the new_ctl setting of SMAP under the climatic conditions with high precipitation and frequent wet snow for the first time.

\subsubsection{Meteorological and snow conditions}

Fig. 3 depicts seasonal variations of observed meteorological conditions and near-surface mass concentration of snow impurities at Nagaoka during the 2011-2012 winter. At Nagaoka air temperature often 

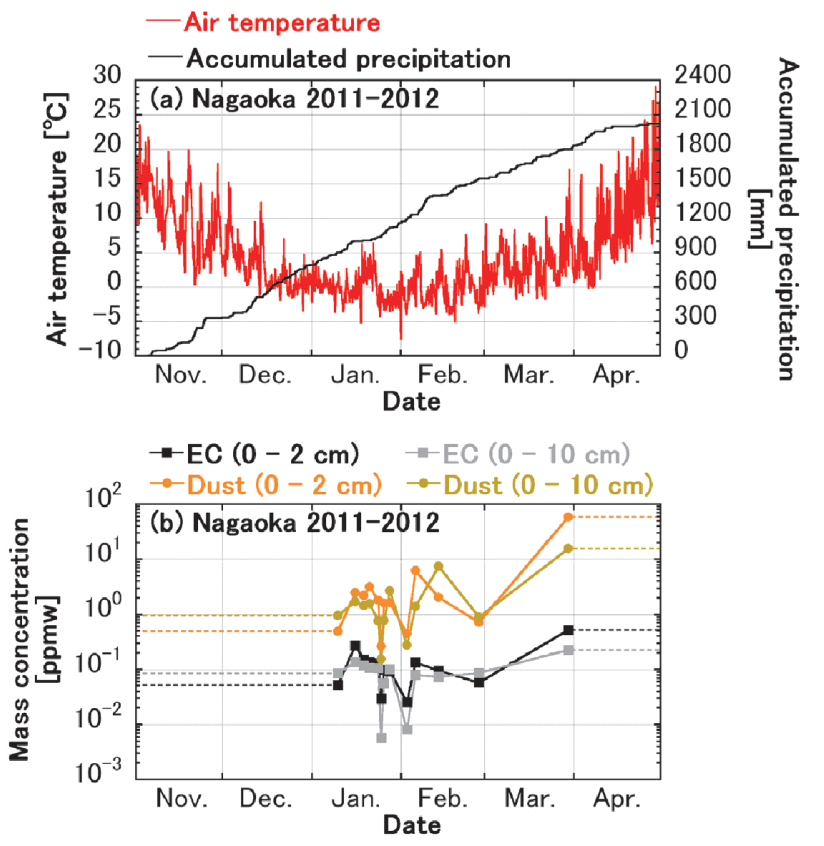

Fig. 3. Observed conditions of (a) air temperature (red solid curve) and accumulated precipitation (black solid curve) and (b) mass concentrations of elemental carbon (EC) and dust for the top 2 and $10 \mathrm{~cm}$ of snowpack during the 2011-2012 winter at Nagaoka, Japan. Dashed lines indicate periods when no measurements were made.

exceeded over $0^{\circ} \mathrm{C}$ even during January and February, and accumulated (corrected) precipitation reached no less than about $2000 \mathrm{~mm}$ during the winter (Fig. 3a), which is much higher than that in Sapporo (Sect. 3.1.1.). The measured mass concentrations of snow impurities (elemental carbon: EC and dust) are illustrated in Fig. 3b. In this study we have assumed $\mathrm{BC}$ to be equivalent to EC following Aoki et al. (2011). During the accumulation period, dust concentration was around $1 \mathrm{ppmw}$ and $\mathrm{BC}$ concentration was approximately $0.1 \mathrm{ppmw}$, while they increased to more than $10 \mathrm{ppmw}$ and approximately $0.2^{-}$ $0.5 \mathrm{ppmw}$ in the ablation period. This feature was almost the same as that observed at Sapporo during the 20072009 winters reported by Aoki et al. (2011).

\subsubsection{Snow depth, snow water equivalent and snow density}

We began SMAP model evaluation at Nagaoka by investigating the accuracy of mass balance simulated by both old_ctl and new_ctl settings during the 2011-2012 winter (Fig. 4). Fig. 4 displays comparisons on snow depth (Fig. 4a), column-integrated SWE (Fig. 4b) and column-average snow density (Fig. 4c), together with the time evolution of model biases. Although simulated complete snow melting was delayed significantly for both settings, new_ctl still performed better than old_ctl at Nagaoka. We examined which process played the most important role in improving model performance at Nagaoka, in the same manner as performed at Sapporo (Sect. 3.1.2.). Table 3 indicates model performances with old_ctl, new_ctl, new_st1, new_st2 and new_st3 settings, which were explained in Sect. 3.1.2. Because the largest
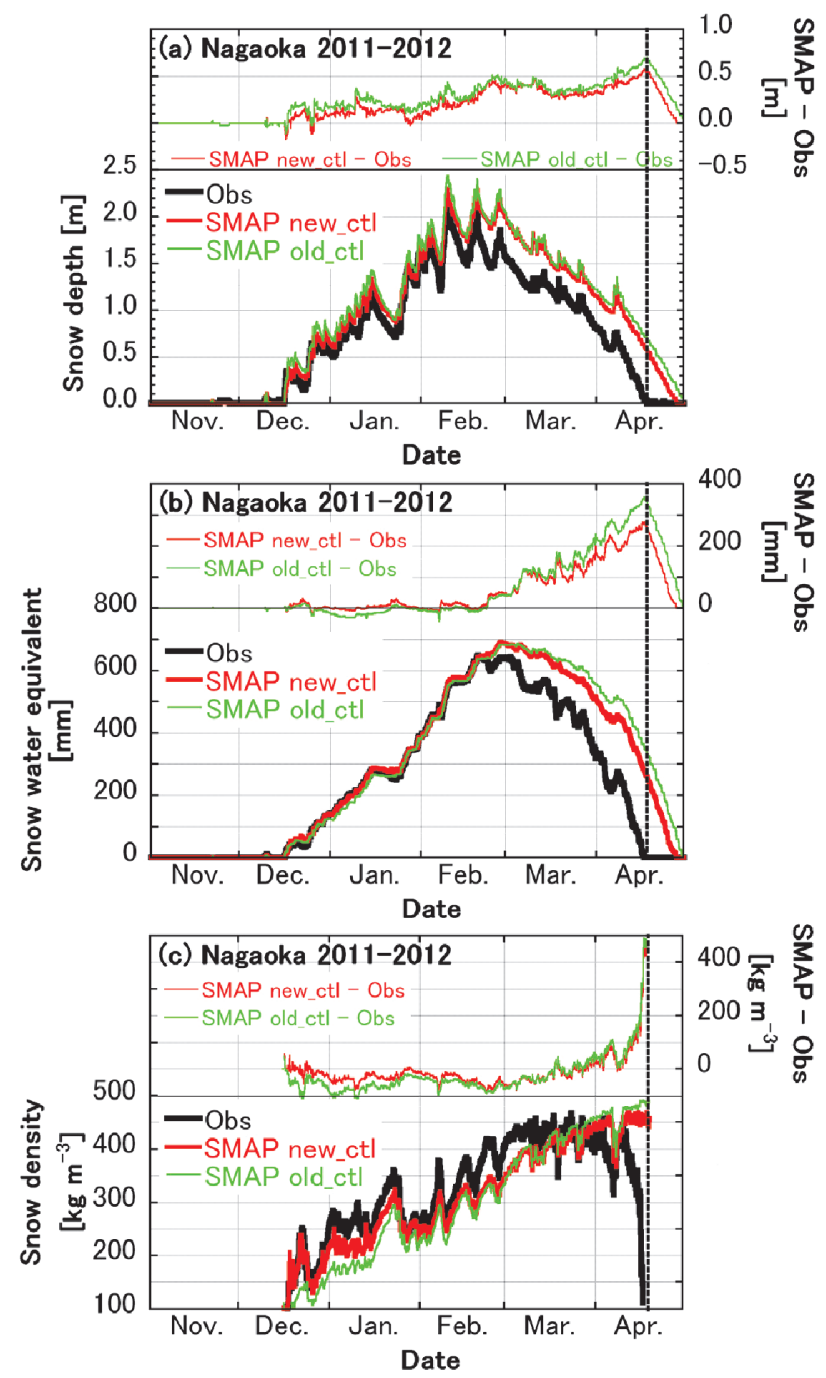

Fig. 4. Comparison of (a) snow depth, (b) column-integrated snow water equivalent and (c) column-average snow density between observations (black solid curves) with simulation results from old and updated version of SMAP (old_ctl: green solid curves and new_ctl: red solid curves) during the 2011-2012 winter at Nagaoka, Japan. Temporal evolutions of model biases (SMAP simulations - observations) are also indicated in each panel. Vertical dashed lines denote the observed timing for complete melting of snowpack.

differences of RMSE and ME between new_ctl and the three sensitivity tests was found in new_st1, we confirmed that the most effective process in improving snow depth simulations during the 2011-2012 winter at Nagaoka was the incorporation of the detailed water movement process in the snowpack, as introduced in Sect. 2.3.1. In the following part we examine the results of new_ctl. During the accumulation period, simulated column-integrated SWE agreed quite well with the observations. However, underestimation of columnaverage snow density leads to some overestimation of the snow depth. After the ablation period, substantial overestimation of column-integrated SWE, as well as snow depth emerged, even though underestimation of column-average snow density was settled and it turned 
Table 3. As Table 1, but for snow depth during 2011-2012 winter at Nagaoka.

\begin{tabular}{clccc}
\hline Parameter & Experiments & Period & RMSE & ME \\
\hline & old_ctl & $\mathbf{2 0 1 1 - 2 0 1 2}$ & $\mathbf{0 . 2 6 8}$ & $\mathbf{0 . 1 8 3}$ \\
& new_ctl & " & $\mathbf{0 . 2 4 8}$ & $\mathbf{0 . 1 8 3}$ \\
Snow depth [m] & new_st1 & " & 0.307 & 0.241 \\
& new_st2 & " & 0.273 & 0.219 \\
& new_st3 & " & 0.258 & 0.193 \\
\hline
\end{tabular}

to be overestimated. Generally, possible reasons for this type of delay in simulated snow melting are: (1) insufficient heating from the underlying ground, (2) failure in simulations of melt water movement and subsequent increase in porosity, (3) excessive formation of nearsurface refreezing layers as a result of defects in the surface energy balance calculation and (4) observation error in input meteorological parameters. We next discuss the respective possibilities of these suggested reasons.

\subsubsection{Soil temperature}

In the simulation performed at Nagaoka for this study, the ground heat flux was calculated from the soil submodel introduced in Sect. 2.3.4. Average simulated ground heat flux (defined to be positive when it is directed downward) was $-8.4 \mathrm{~W} \mathrm{~m}^{-2}$ during January and February, and $-5.8 \mathrm{~W} \mathrm{~m}^{-2}$ during March and April. We first checked whether the soil submodel could reproduce soil temperature and ground heat flux adequately. Fig. 5 illustrates the seasonal evolution of soil temperatures (at $10,20,50,80$ and $100 \mathrm{~cm}$ in depth) at Nagaoka during the 2011-2012 winter simulated by new_ctl. Although new_ ctl was prone to underestimate soil temperature, especially during mid-December to early March, the observed seasonal evolution was roughly reproduced and calculated soil temperatures could meet observations during the ablation period. From these results we indirectly confirmed that the ground heat flux, at least during the ablation period, could be simulated reasonably and we could thus abandon the first possibility mentioned above.

\subsubsection{Volumetric water content in the snowpack}

Next, we investigated the accuracy of simulated volumetric water content profiles by comparing them with measurements obtained from snow pit observations. In this process we adjusted the simulated snow depths into observed snow depths. Fig. 6 shows selected comparisons during the ablation period. As shown in the figures, there were no large discrepancies in the amount of volumetric water content between observations and simulations, implying that the newly incorporated water movement scheme worked reasonably and it could not thus be the main cause of the snow-melt delay. To improve the performance of new ctl and reproduce observed frequent fluctuations found in the volumetric water content profiles, it would be necessary to calculate the new snow density and snow
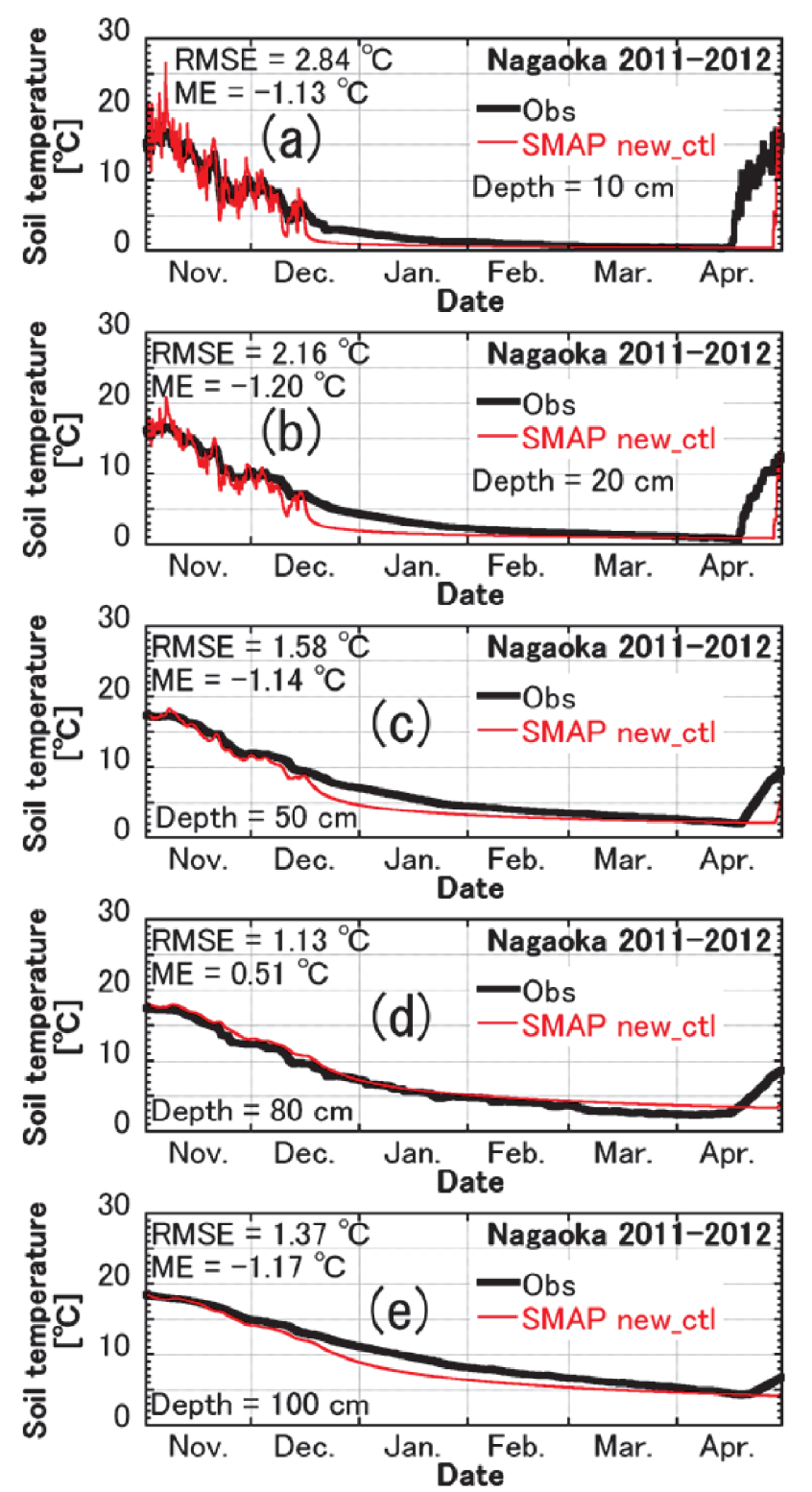

Fig. 5. Seasonal evolution of soil temperatures at (a) $10 \mathrm{~cm}$, (b) $20 \mathrm{~cm}$, (c) $50 \mathrm{~cm}$, (d) $80 \mathrm{~cm}$ and (e) $100 \mathrm{~cm}$ in depth simulated by the updated version of SMAP (new_ctl: red solid curves) together with observations (black solid curves) during the 2011-2012 winter at Nagaoka, Japan.

grain size, as well as their evolution (snow settlement and snow metamorphism) more accurately, because the present formulations governing the water movement in the snowpack are controlled by snow grain size and snow density, as explained in Sect. 2.3.1. In addition, it would be necessary to take heterogeneous $3 \mathrm{~d}$ water movement in the snowpack into account in some way. 

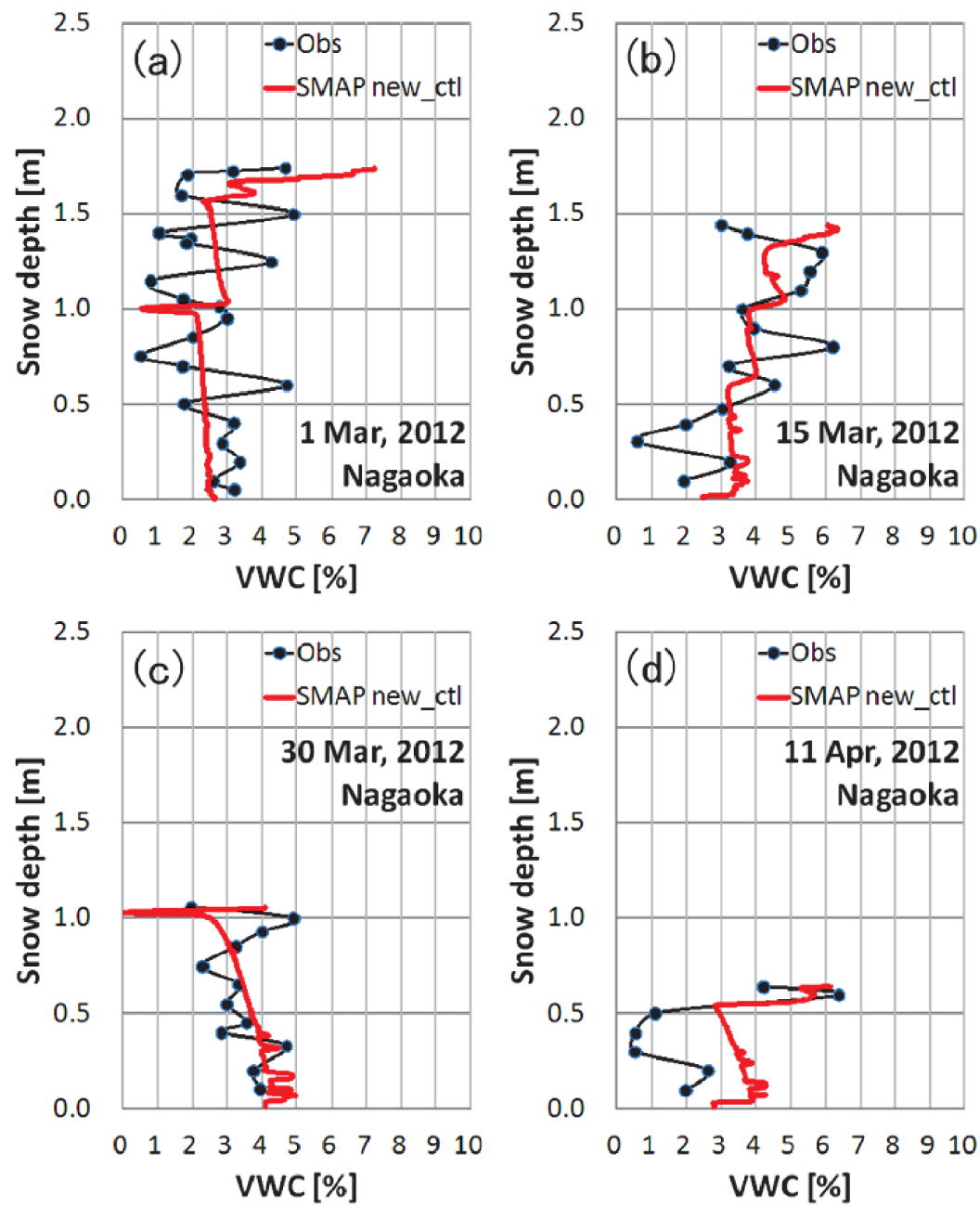

Fig. 6. Profile comparison for volumetric water content (VWC) between observations (black solid curves with filled circles) and simulations by the updated version of SMAP (new_ctl: red solid curves) during the ablation period of the 2011-2012 winter: (a) March 1, (b) March 15, (c) March 30 and (d) April 11 at Nagaoka, Japan. Simulated snow depths are adjusted to the observations.

\subsubsection{Snow surface temperature}

Finally, we looked at the surface energy balance simulated by new_ctl in terms of snow surface temperature. Fig. 7a compares observed and simulated snow surface temperatures at Nagaoka during the 2011-2012 winter. Although RMSE and $M E$ during the entire winter season were sufficiently low $\left(1.49^{\circ} \mathrm{C}\right.$ and $-0.31^{\circ} \mathrm{C}$, respectively) compared with simulation results at Sapporo in the 2007-2009 winters (Table 2), underestimation was enhanced, especially when the snow surface did not reach $0^{\circ} \mathrm{C}$. In fact, $R M S E$ and $M E$ for the case when the observed snow surface temperature was negative was $2.17^{\circ} \mathrm{C}$ and $-0.65^{\circ} \mathrm{C}$, respectively. This underestimation could even be found during ablation period (Fig. 7b). This means that, in SMAP, the heating energy available during the daytime was first used to heat the cooled snow surface temperature; thus, there was insufficient energy remaining for the surface melt. Besides, the present result suggests that new treatment introduced in Sect. 2.3.3. was not effective in this case. During the 2011-2012 winter, average observed wind speed at Nagaoka was lower $\left(0.67 \mathrm{~m} \mathrm{~s}^{-1}\right)$ compared to those at
Sapporo during the 2007-2009 winters (1.94 and $2.69 \mathrm{~m} \mathrm{~s}^{-1}$ ). Since turbulent heat fluxes calculated by SMAP are controlled by not only the bulk transfer coefficient but also wind speed (Eq. 15), the present treatment could not be effective under weak wind condition at Nagaoka during the 2011-2012 winter. Therefore, it is necessary to develop more accurate formulation for turbulent heat fluxes. At present, we do not have substantive information to judge which mechanism was the main cause for this failure in the surface energy balance calculation: the formulation of SMAP itself or observational errors in the input meteorological data. According to Yamaguchi et al. (2004), they also encountered almost the same situation in their SNOWPACK model simulations at Nagaoka and Shinjo. The maximum snow depth error increased with increasing observed maximum snow depth (more than about $1 \mathrm{~m}$ ). Therefore, it is necessary to perform further investigations on snow-melt processes for thick seasonal snowpack. For this purpose, it would be effective to acquire more comprehensive knowledge regarding characteristics of SMAP model performance by extending 


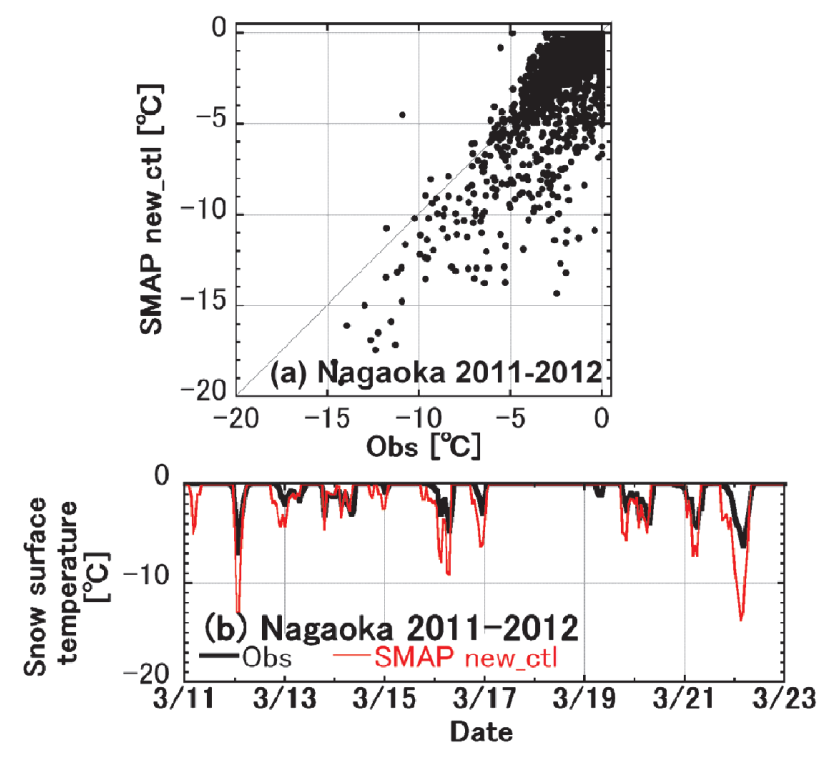

Fig. 7. (a) Scatter plot for snow surface temperature between observation and simulation by the updated version of SMAP (new_ctl) during the 2011-2012 winter at Nagaoka, Japan. (b) Example of diurnal cycles of snow surface temperature comparing between observation and simulation.

model evaluations to more seasons and more sites.

\section{Conclusions}

To solve the problems of SMAP pointed out by Niwano et al. (2012) with their model evaluations at Sapporo during the 2007-2009 winters, namely (1) overestimation of snow depth, especially during the warm 2008-2009 winter when the air temperatures were often above $0{ }^{\circ} \mathrm{C}$, even in the accumulation period and (2) enhanced underestimation of snow surface temperature under very stable conditions, we performed the following model updates:

- implementation of a detailed scheme of water movement in the snowpack based on the Richards equation and the van Genuchten model (van Genuchten, 1980; Shimizu, 1970; Hirashima et al., 2010; Yamaguchi et al., 2010, 2012);

- incorporation of a physically realistic snow settlement formulation that considers the effects of snow density, snow temperature, absolute liquid water content and geometric snow grain size (Vionnet et al., 2012); and

- modification of the treatment of turbulent heat exchanges under very stable conditions by setting a limitation for the Richardson number to ensure minimum turbulent exchanges.

Using the same data as Niwano et al. (2012) employed, we evaluated the performance of the updated SMAP model, new_ctl. Additional sensitivity tests to inspect the individual effects of the above-mentioned three updates were also conducted. Consequently, we found that snow depth simulations were improved in new_ctl for both the 2007-2008 and 2008-2009 winters, as the scores indicating model accuracy (ME and RMSE) were reduced significantly. The most effective update for this improvement at Sapporo was the introduction of the snow settlement scheme by Vionnet et al. (2012). The underestimation of the snow surface temperature was also improved, mainly by revising the treatment of turbulent heat exchanges under very stable conditions. However, we highlighted that the choice of maximum Richardson number should be examined in more detail, because surface heating was more enhanced in new_ctl compared to old_ctl, the sign of $M E$ turned from negative to positive and the absolute model bias increased during the 2007-2008 winter.

Next, SMAP was applied to Nagaoka, which is located in one of the heaviest snow-fall regions in Japan and is subject to melt forms throughout the winter season. The purpose of this application was to test the reliability of SMAP by demonstrating its usability under different climate conditions. Because ground heat flux, which is used for the bottom boundary condition for solving energy conservation equation of the snowpack in SMAP, was not available at Nagaoka during the 20112012 winter when the present numerical studies were performed, we developed a soil submodel that provides realistic ground heat flux into the snowpack. The soil submodel employs an energy conservation equation that considers phase changes and convection flow as its governing equation. Furthermore, water flow in the soil is controlled by the Richards equation, as well as by the van Genuchten model (van Genuchten, 1980). Results from the snow-soil-coupled simulations by SMAP new_ctl proved that model-estimated ground heat flux could be reasonably calculated and also that water movement in quite thick snowpack (more than $2.0 \mathrm{~m}$ ) could also be simulated reasonably well. In addition, we found that new_ctl performed better compared than old_ctl at Nagaoka in terms of mass balance simulations. The most effective process in this improvement was the implementation of a detailed scheme of water movement in the snowpack (van Genuchten, 1980; Shimizu, 1970; Hirashima et al., 2010; Yamaguchi et al., 2010, 2012). However, we still found underestimation of the snow surface temperature, as well as substantial overestimation of column-integrated SWE and snow depth by SMAP new_ctl after ablation period. We discussed two possible reasons for these failures: a defect in the SMAP model calculations in the surface energy balance simulation and observational errors in the model input data. Because a situation similar to the present study was reported in the previous simulation study by Yamaguchi et al. (2004) with the SNOWPACK model, we conclude that it is necessary to perform further investigation on snow-melt processes for thick seasonal snowpack.

\section{Acknowledgements}

We gratefully appreciate the very helpful comments 
by Takeshi Yamazaki and an anonymous reviewer. This study is supported in part by (1) Japan Society for the Promotion of Science (JSPS), Grant-in-Aid for Scientific Research (S), number 23221004, (2) the Grant for Joint Research Program, the Institute of Low Temperature Science, Hokkaido University, (3) the Experimental Research Fund for Global Environment Conservation, the Ministry of the Environment of Japan and (4) the Global Change Observation Mission - Climate (GCOM-C) / the Second-generation GLobal Imager (SGLI) Mission, the Japan Aerospace Exploration Agency (JAXA).

\section{References}

Aoki, T., Motoyoshi, H., Kodama, Y., Yasunari, T. J., Sugiura, K. and Kobayashi, H. (2006): Atmospheric aerosol deposition on snow surfaces and its effect on albedo, SOLA, 2, 13-16, doi:10.2151/sola.2006-004.

Aoki, T., Hori, M., Motoyoshi, H., Tanikawa, T., Hachikubo, A., Sugiura, K., Yasunari, T. J., Storvold, R., Eide, H. A., Stamnes, K., Li, W., Nieke, J., Nakajima, Y. and Takahashi, F. (2007): ADEOS-II/GLI snow/ice products-Part II: Validation results using GLI and MODIS data. Remote Sens. Environ., 111, 274-290, doi:10.1016/j.rse.2007b.02.035.

Aoki, T., Kuchiki, K., Niwano, M., Kodama, Y., Hosaka, M. and Tanaka, T. (2011): Physically based snow albedo model for calculating broadband albedos and the solar heating profile in snowpack for general circulation models.J. Geophys. Res., 116, D11114, doi:10.1029/2010JD015507.

Armstrong, R. L. and Brun, E. (Eds.) (2008): Snow and Climate: Physical Processes, Surface Energy Exchange and Modeling. Cambridge Univ. Press, Cambridge, U. K.

Bader, H.-P. and Weilenmann, P. (1992): Modeling temperature distribution, energy and mass flow in a (phase-changing) snowpack. I. Model and case studies. Cold Reg. Sci. Technol., 20, 157-181, doi:10.1016/0165-232X(92)90015-M.

Bartelt, P. and Lehning, M. (2002): A physical SNOWPACK model for the Swiss avalanche warning. Part I: Numerical model. Cold Reg. Sci. Technol., 35, 123-145, doi:10.1016/S0165232X(02)00074-5.

Brun, E., Martin, E., Simon, V., Gendre, C. and Coleou, C. (1989): An energy and mass model of snow cover suitable for operational avalanche forecasting. J. Glaciol., 35, 333-342.

Brun, E., David, P., Sudul, M. and Brunot, G. (1992): A numerical model to simulate snow-cover stratigraphy for operational avalanche forecasting. J. Glaciol., 38, 13-22.

Brun, E., Six, D., Picard, G., Vionnet, V., Arnaud, L., Bazile, E., Boone, A., Bouchard, A., Genthon, C., Guidard, V., Le Moigne, P., Rabier, F. and Seity, Y. (2011): Snow/atmosphere coupled simulation at Dome C, Antarctica, J. Glaciol., 52(204), doi:10.3189/002214311797409794.

Denoth, A. (1994): An electronic device for long-term snow wetness recording. Ann. Glaciol., 19, 104-106, doi:10.3189/172756404781815121.

Fierz, C. and Lehning, M. (2001): Assessment of the microstructure-based snow-cover model SNOWPACK: thermal and mechanical properties. Cold Reg. Sci. Technol. 33, 123-131, doi:10.1016/S0165-232X(01)00033-7.

Goudriaan, J. (1977): Crop Micrometeorology: A Simulation Study. Pudoc, Wageningen, Netherlands.

Groot Zwaaftink, C. D., Cagnati, A., Crepaz, A., Fierz, C. Macelloni, G., Valt, M. and Lehning, M. (2013): Event-driven deposition of snow on the Antarctic Plateau: analyzing field measurements with SNOWPACK. Cryosphere, 7, 333-347. doi:10.5194/tc-7-333-2013

Hachikubo, A. (2001): Numerical modelling of sublimation on snow and comparison with field measurements. Ann. Glaciol., 32, 27-32, doi:10.3189/172756401781819265.
Helgason, W. and Pomeroy, J. (2012): Problems closing the energy balance over a homogeneous snow cover during midwinter. J. Hydrometeorol., 13, 557-572, doi:10.1175/JHM-D-11-0135.1.

Hirashima, H., Nishimura, K., Baba, E., Hachikubo, A. and Lehning, M. (2004): SNOWPACK model simulation for snow in Hokkaido, Japan. Ann. Glaciol., 38, 123-129, doi:10.3189/ 172756404781815121.

Hirashima, H., Yamaguchi, S., Sato, A. and Lehning, M. (2010): Numerical modeling of liquid water movement through layered snow based on new measurements of the water retention curve. Cold. Reg. Sci. Technol., 64(2), 94-103, doi 10.1016/j.coldregions.2010.09.003

Iwata, Y., Hirota, T., Hayashi, M., Suzuki, S. and Hasegawa, S. (2010): Effects of frozen soil and snow cover on cold-season soil water dynamics in Tokachi, Japan. Hydrol. Process., 24 1755-1765. doi:10.1002/hyp.7621.

Jacobi, H.-W., Domine, F., Simpson, W. R., Douglas, T. A. and Sturm, M. (2010): Simulation of the specific surface area of snow using a one-dimensional physical snowpack model: Implementation and evaluation for subarctic snow in Alaska, Cryosphere, 4, 35-51, doi:10.5194/tc-4-35-2010.

Jansson, P.-E. and Karlberg, L. (2001): Coupled Heat and Mass Transfer Model for Soil-Plant-Atmosphere Systems. Department of Civil and Environmental Engineering, Royal Institute of Technology, Engineering, Stockholm, Sweden.

Kajikawa, M. (1989): Relationship between new snow density and shape of snow crystals [in Japanese with English abstract]. Seppyo, 51, 178-183.

Kuchiki, K., Aoki, T., Tanikawa, T. and Kodama, Y (2009): Retrieval of snow physical parameters using a ground-based spectral radiometer, Appl. Opt., 48, 5567-5582, doi:10.1364/ A0.48.005567.

Lehning, M., Bartelt, P., Brown, B., Fierz, C. and Satyawali, P. (2002a): A physical SNOWPACK model for the Swiss avalanche warning. Part II: Snow microstructure. Cold Reg. Sci. Technol., 35, 147-167, doi:10.1016/S0165-232X(02)00073-3.

Lehning, M., Bartelt, P., Brown, B. and Fierz, C. (2002b): A physical SNOWPACK model for the Swiss avalanche warning. Part III: Meteorological forcing, thin layer formation and evaluation. Cold Reg. Sci. Technol., 35, 169-184, doi:10.1016/ S0165-232X(02)00072-1.

Lundy, C. C., Brown, R. L., Adams, E. E., Birkeland, K. W. and Lehning, M. (2001): A statistical validation of the snowpack model in a Montana climate. Cold Reg. Sci. Technol., 33, 237246, doi:10.1016/S0165-232X(01)00038-6

Martin, E. and Lejeune, Y. (1998): Turbulent fluxes above the snow surface. Ann. Glaciol., 26, 179-183.

Morin, S., Domine, F., Dufour, A., Lejeune, Y., Lesaffre, B., Willemet, J.-M., Carmagnola, C. M. and Jacobi, H.-W. (2013): Measurements and modeling of the vertical profile of specific surface area of an alpine snowpack. Adv. Water. Resour., 55, 111-120, doi:10.1016/j.advwatres.2012.01.010.

Morris, E. M., Bader, H.-P. and Weilenmann, P. (1997): Modelling temperature variations in polar snow using DAISY. $J$. Glaciol., 43, 180-191.

National Research Institute for Earth Science and Disaster Prevention, Japan. (2012): Data on Snow Cover in Nagaoka (34) (2011/12 Winter Season). Tech Note of NIED., 372, $31 \mathrm{pp}$.

Niwano, M., Aoki, T., Kuchiki, K., Hosaka, M. and Kodama, Y. (2012): Snow Metamorphism and Albedo Process (SMAP) model for climate studies: Model validation using meteorological and snow impurity data measured at Sapporo, Japan. J. Geophys. Res., 117, F03008, doi:10.1029/ 2011JF002239.

Peters-Lidard, C. D., Blackburn, E., Liang, X. and Wood, E. F. (1998): The Effect of Soil Thermal Conductivity Parameterization on Surface Energy Fluxes and Temperatures. J. Atmos. Sci., 55, 1209-1224, doi:10.1175/1520-0469 (1998) 055 $<1209$ : TEOSTC $>2.0 . \mathrm{CO} ; 2$

Pinzer, B. R. and Schneebeli, M. (2009): Snow metamorphism under alternating temperature gradients: Morphology and recrystallization in surface snow, Geophys. Res. Lett., 36, 
L23503, doi:10.1029/2009GL039618.

Rasmus, S., Räisänen, J. and Lehning, M. (2004): Estimating snow conditions in Finland in the late 21st century using the SNOWPACK model with regional climate scenario data as input. Ann. Glaciol., 38, 238-244, doi:10.3189/ 172756404781814843.

Richards, L. A. (1931): Capillary conduction of liquids through porous mediums. J. Appl. Phys., 1, 318-333, doi:10.1063/ 1.1745010 .

Rousselot, M., Durand, Y., Giraud, G., Merindol, L. and Daniel, L. (2010): Analysis and forecast of extreme new-snow avalanches: a numerical study of the avalanche cycles of February 1999 in France. J. Glaciol., 56, 758-770, doi:10.3189/ 002214310794457308 .

Saito, K., Yamaguchi, S., Iwata, H., Harazono, Y., Kosugi, K., Lehning, M. and Shulski, M. (2012): Climatic physical snowpack properties for large-scale modeling examined by observations and a physical model. Polar Science, 6, 79-95, doi:10.1016/j.polar.2012.02.003.

Shimizu, H. (1970): Air permeability of deposited snow Contributions from the Institute of Low Temperature Science, A22, 1-32.

van Dam, J. C. and Feddes, R. A. (2000): Numerical simulation of infiltration, evaporation and shallow groundwater levels with the Richards equation. J. Hydrol., 233, 72-85, doi:10.1016/ S0022-1694(00)00227-4.

van Genuchten, M. T. (1980): A closed-form equation for predicting the hydraulic conductivity of unsaturated soil Soil Sci. Soc. Am. J., 44, 892-898.

Vionnet, V., Brun, E., Morin, S., Boone, A., Faroux, S., Le Moigne P., Martin, E. and Willemet, J.-M. (2012): The detailed snowpack scheme Crocus and its implementation in SURFEX v7.2. Geosci. Model Dev., 5, 773-791, doi:10.5194/gmd-5-7732012.

Wagnon, P., Lafaysse, M., Lejeune, Y., Maisincho, L., Rojas, M. and Chazarin, J. P. (2009): Understanding and modeling the physical processes that govern the melting of snow cover in a tropical mountain environment in Ecuador, J. Geophys. Res., 114, D19113, doi:10.1029/2009JD012292.

Warren, S. G. and Wiscombe, W. J. (1980): A model for the spectral albedo of snow. II: Snow containing atmospheric aerosols. J. Atmos. Sci., 37, 2734-2745, doi:10.1175/1520-0469 (1980)037<2734: AMFTSA> 2.0.CO;2.

Wiscombe, W. J. and Warren, S. G. (1980): A model for the spectral albedo of snow. I: Pure snow. J. Atmos. Sci., 37, 27122733, doi:10.1175/1520-0469(1980)037<2712 : AMFTSA> 2.0.CO;2.

Yamaguchi, S., Sato, A. and Lehning, M. (2004): Application of the numerical snowpack model (SNOWPACK) to the wet-snow region in Japan. Ann. Glaciol., 38, 266-272, doi:10.3189/ 172756404781815239 .

Yamaguchi, S., Katsushima, T., Sato, A. and Kumakura, T. (2010): Water retention curve of snow with different grain sizes. Cold. Reg. Sci. Technol., 64(2), 87-93, doi:10.1016/j.coldregions, 2010.05.008.

Yamaguchi, S., Watanabe, K., Katsushima, T., Sato, A. and Kumakura, T. (2012): Dependence of the water retention curve of snow on snow characteristics. Ann. Glaciol., 53(61), 6-12, doi:10.3189/2012AoG61A001.

Yamazaki, T. (1998): A multi-layer heat balance model of snow cover adaptable to intensely cold regions [in Japanese with English abstract], Seppyo, 60, 131-141.

Yamazaki, T. (2001): A one-dimensional land surface model adaptable to intensely cold regions and its applications in eastern Siberia, J. Meteorol. Soc. Jpn., 79(6), 1107-1118, doi 10.2151/jmsj.79.1107.

Yokoyama, K., Ohno, H., Kominami, Y., Inoue, S. and Kawakata, T. (2003): Performance of Japanese precipitation gauges in winter [in Japanese with English abstract]. Seppyo, 65, 303316. 